\title{
Pueblos indígenas y derechos humanos en Honduras en un contexto de anormalidad democrática
}

Joaquín A. Mejía Riveral

\section{Resumo}

Desde 2009, Honduras vive uma grave crise constitucional que mantém o país numa situação de permanente anormalidade democrática, caracterizada, entre outras coisas, por uma deterioração crescente da institucionalidade pública e pela prevalência de um cinismo estrutural que se traduz no fato de que o Estado ratifique a maioria dos tratados internacionais de direitos humanos mas adote leis e práticas contrárias a eles, particularmente quando se trata de impor um modelo de desenvolvimento fundamentado num extrativismo cujas origens remontam ao século $\mathrm{XX}$ e que tem um impacto significativo na vida e nos territórios dos povos originários. Como indica o historiador Marvin Barahona, o pano de fundo desta situação é o antagonismo entre o Estado e os povos indígenas como produto do exercício exclusivo do poder pela elite criolla que deu forma às instituições e ao ordenamento jurídico nacional a fim de garantir a imposição de tal modelo. Neste confronto desigual, o Estado e suas instituições se colocam ao lado das empresas, e os povos indígenas resistem valendo-se da reivindicação do poder discursivo de dois relatos políticos à luz dos estándares constitucionais e interamericanos: a soberania popular e a autodeterminação.

Palavras-chave: povos indígenas, soberania popular, democracia, direitos humanos, autodeterminação.

\section{Resumen}

Desde el año 2009 Honduras ha vivido una grave crisis constitucional que le mantiene en una permanente situación de anormalidad democrática, caracterizada, entre otras cosas, por un creciente deterioro de la institucionalidad pública y la prevalencia de un cinismo estructural que se traduce en que el Estado ratifica la mayoría de tratados internacionales de derechos humanos, pero adopta leyes y prácticas contrarias a ellos, particularmente cuando se trata de imponer un modelo de desarrollo basado en un extractivismo cuyos orígenes se encuentran en la Honduras del siglo XX y que tiene un impacto significativo en la vida y los territorios de los pueblos originarios. Como lo señala el historiador Marvin Barahona, el telón de fondo de esto ha sido el antagonismo entre Estado y pueblos indígenas como producto del ejercicio exclusivo del poder por la élite criolla que ha moldeado las instituciones y el ordenamiento jurídico nacional para garantizar la imposición de dicho modelo. En esta confrontación desigual, el Estado y sus instituciones se colocan al lado de las empresas, y los pueblos indígenas resisten a través de la reivindicación del poder discursivo de dos relatos políticos a la luz de los estándares constitucionales e interamericanos: la soberanía popular y la autodeterminación.

Palabras clave: pueblos indígenas, soberanía popular, democracia, derechos humanos, autodeterminación.

1 Doctor y maestro en Estudios Avanzados en Derechos Humanos por la Universidad Carlos III de Madrid. jamejiarivera@gmail.com.. 


\section{Los derechos de los pueblos indígenas y Garífuna en un contexto de anormalidad democrática}

Honduras vive una crisis política continuada debido al golpe de Estado en 2009 (MEJÍA y FERNÁNDEZ, 2010), la aprobación ilegal de la reelección presidencial en 2015 (MEJÍA y JEREZ, 2018) y la imposición en la presidencia de Juan Orlando Hernández en 2018 a pesar de las graves irregularidades evidenciadas en el último proceso electoral (MOE-OEA, 2017). Esta crisis no puede comprenderse sin el profundo proceso de deterioro de la institucionalidad democrática que nos acerca a la consolidación de un régimen autoritario con tintes dictatoriales y la consecuente comisión de graves violaciones a derechos humanos documentadas por la Comisión Interamericana de Derechos Humanos (CIDH, 2009, 2015, 2018, 2019) y la Oficina del Alto Comisionado de Naciones Unidas para los Derechos Humanos en Honduras (OACNUDH, 2018, 2019).

Esta situación de anormalidad democrática se caracteriza por tres cuestiones: en primer lugar, por una especie de cinismo estructural en el sentido que el Estado ratifica la mayoría de tratados internacionales de derechos humanos, pero aprueba leyes y adopta prácticas que son contrarias a ellos; en segundo lugar, por un creciente deterioro de la institucionalidad democrática y un incremento de la desconfianza ciudadana. En tercer lugar, por el uso político perverso de la violencia y la criminalidad con el fin de promover la remilitarización de la sociedad y el Estado, y un populismo penal a través del cual se realizan reformas penales cuya falta de claridad, certeza y precisión de las conductas prohibidas brinda una amplia discrecionalidad a las autoridades estatales para determinar la configuración de delitos que no corresponden con la gravedad y la naturaleza de los hechos, las cuales pueden ser utilizadas "para sancionar reivindicaciones y movimientos sociales o la labor de los defensores de derechos humanos" (CIDH y OACNUDH, 2017: 1) y de esta forma reducir al mínimo la presión de los sectores sociales y la crítica pública, que son fundamentales en una sociedad democrática (MEJÍA, 2017).

En este contexto se están produciendo numerosos conflictos derivados de la imposición de un modelo económico que se centra en la explotación de los bienes naturales con graves consecuencias para los derechos humanos de las comunidades en cuyos territorios se ejecutan o se pretenden ejecutar proyectos hidroeléctricos, de bosque, mineros y de hidrocarburos. En la base de tales conflictos se encuentra la confrontación del mundo indígena que, con sus matices, representa un modelo que se acerca más a una integración en la naturaleza, con el mundo occidental-productivista que representa un modelo que ve en los bienes comunes recursos para extraer beneficios. A su vez, el telón de fondo de esto ha sido el antagonismo entre Estado y pueblos indígenas como producto del ejercicio exclusivo del poder por la élite criolla que ha moldeado las instituciones y el ordenamiento jurídico nacional para garantizar la imposición de este último modelo (BARAHONA, 2009: 15-21). La resistencia de los pueblos descalifica radicalmente el discurso y la práctica del Estado, y pone en riesgo su hegemonía, por ello este último reacciona 
violentamente a través de abusos a derechos humanos, frente a los cuales el Estado y sus instituciones, "se alinean sistemática e incondicionalmente con las empresas" (COSTA, 2016: 197) mediante el uso excesivo de la fuerza policial y militar, y la utilización indebida del derecho penal contra quienes defienden sus territorios.

Uno de los detonantes de esta situación es la falta de voluntad política del Estado hondureño de respetar y garantizar los derechos a la participación ciudadana y a la consulta previa e informada de las comunidades donde se pretenden realizar los proyectos extractivos, a pesar que la Constitución de la República de 1982, la Convención Americana sobre Derechos Humanos y el Convenio 169 de la Organización Internacional del Trabajo sobre pueblos indígenas y tribales, ratificadas el 5 de septiembre de 1977 y el 28 de marzo de 1995 respectivamente, reconocen derechos colectivos que son esenciales para la supervivencia física y cultural de los pueblos indígenas y Garífuna ${ }^{2}$, entre los que destacan, los derechos a la propiedad colectiva de sus tierras, territorios y bienes naturales, a mantener sus culturas, al autogobierno y la autodeterminación, y a que se les solicite su consentimiento libre, previo e informado en decisiones que les puedan afectar.

En el mismo sentido, la Sala de lo Constitucional de la Corte Suprema de Justicia, en el marco de su ejercicio del control de convencionalidad para determinar la compatibilidad de las normas nacionales con el Convenio 169 y la Convención Americana, ha determinado que el Estado tiene la obligación de proteger los bienes naturales existentes en las tierras de los pueblos indígenas y tribales, y de garantizar su participación efectiva en los procesos de adopción de decisiones en el contexto de proyectos de desarrollo que puedan generar prejuicios en el medio ambiente y en la salud de los mismos (SCO, 2017). Por su parte, la Corte Interamericana de Derechos Humanos ha dictado dos sentencias en las que encontró al Estado responsable internacionalmente por violentar al pueblo Garífuna su derecho a la consulta y a la propiedad colectiva (CIDH, 2015).

Tomando en consideración que, de acuerdo con la Sala de lo Constituciona ${ }^{1}$, las normas $\mathrm{y}$ derechos fundamentales de origen supranacional se incorporan a nuestro derecho interno para formar parte del llamado "Bloque de Constitucionalidad" (SCO, 2013: 11-12, 20) y que son vinculantes no solo las sentencias en las que el Estado es parte en el litigio, sino también aquellas en que no lo es, ya que pueden ser "relacionadas y desarrolladas pertinentemente como derecho vinculante" (SCO, 2015: 20), las dos sentencias logradas por el pueblo Garífuna en los casos Triunfo de la Cruz y Punta Piedra, así como el resto de jurisprudencia interamericana sobre derechos de los pueblos indígenas, deben asumirse como poderosas herramientas jurídicas y políticas para promover cambios estructurales que favorezcan el respeto de los derechos de estos pueblos en relación con sus territorios, lo cual pasa por su reconocimiento como sujetos titulares de derechos frente a los que el Estado debe garantizar las condiciones necesarias para que puedan desarrollar su cosmovisión desde su autonomía y auto-identificación como grupo diferenciado del resto de

$2 \quad$ El pueblo Garífuna surge de la unión de africanos provenientes de barcos españoles que naufragaron en la Isla San Vicente en 1635 y los amerindios que habitaban la zona desde antes de la colonización. Se encuentra asentado en aproximadamente 40 comunidades ubicadas a lo largo de la costa caribe de Honduras en los departamentos de Cortés, Atlántida, Colón y Gracias a Dios (Banco Mundial, 2007: 17-20). 
la sociedad.

A la luz de los estándares desarrollados en la normativa y jurisprudencia internacional que es vinculante para el Estado hondureño, y en la jurisprudencia constitucional se pueden identificar dos narrativas o relatos políticos, uno nacional - la soberanía popular - y otro internacional - la autodeterminación de los pueblos - , que son fundamentales para que se cumplan las salvaguardias requeridas para llevar a cabo cualquier plan de desarrollo, inversión, exploración o extracción en sus territorios, a saber: (a) efectuar un proceso adecuado y participativo que garantice su derecho a la consulta previa, libre, informada y de buena fe, y a través de sus propias instituciones y órganos de representación; (b) compartir razonablemente los beneficios que se produzcan de la gestión de los bienes naturales; y (c) realizar un estudio previo de impacto ambiental, económico, cultural y social por parte de entidades independientes y técnicamente capaces, bajo la supervisión estatal.

\section{El poder discursivo de la soberanía popular y la autodeterminación de los pueblos}

Todo discurso provoca efectos de poder, es decir, genera una práctica. Cuando las verdades de un discurso son aceptadas, afecta la vida, la conducta y los valores de las personas, y la identidad de los grupos sociales. De esta manera, "[1]a verdad de un discurso desencadena prácticas, induce comportamientos, provoca acciones, legitima actitudes, consolida instituciones, etc." (BARTOLOMÉ, 2006: 33-34, 61, 68). Bajo esta lógica, el Estado de Honduras ha asumido un discurso del desarrollo cuyos efectos de poder le permiten legitimar una práctica agresiva de entrega inconsulta de los territorios y los bienes comunes a empresas privadas nacionales y transnacionales, y convertir a las personas que se oponen a ella en enemigas del desarrollo y de la reducción de la pobreza.

Para contrarrestar los efectos de poder de dicho discurso, los pueblos indígenas y Garífuna han comprendido la importancia de recuperar el poder discursivo de dos conceptos legales y políticos - la soberanía popular y la autodeterminación - que son fundamentales para fortalecer las luchas comunitarias de defensa de sus territorios y bienes naturales, y reivindicar el ejercicio de su derecho político a ser consultadas y a participar en las decisiones que tienen un impacto significativo en su salud, el medioambiente, su forma de vida y su relación con la tierra y el territorio. Por ello, haciendo uso de los estándares constitucionales e internacionales plantean que el progreso social y la prosperidad económica sólo pueden sustentarse si se respeta la cosmovisión de los pueblos con respecto a su relación con los territorios, si los bienes comunes son gestionados con cuidado y responsabilidad, y si se garantizan los derechos humanos, dado que no hay propiamente desarrollo sin respeto pleno por los mismos (CIDH, 1997).

\section{La soberanía popular}

El artículo 2 de la Constitución de la República establece que la soberanía corresponde 
al pueblo del cual emanan todos los poderes del Estado que se ejercen por representación. La soberanía popular debe entenderse en dos sentidos: por un lado, es una garantía negativa, lo que implica una prohibición para cualquiera de apropiarse de ella y usurparla, ya que solo pertenece al pueblo y solo reside en el pueblo; por tanto, nadie, aunque sea un representante elegido por el pueblo, puede adueñarse de ella para ejercerla contra alguno de sus miembros. Por otro lado, es una garantía positiva en tanto que pertenece al conjunto de personas de las que el pueblo se compone y equivale a la suma de los poderes y contrapoderes que son los derechos humanos normativamente reconocidos. En consecuencia, estos derechos equivalen "a otros tantos fragmentos de soberanía popular correspondientes a todos y a cada ciudadano. Por eso cualquier violación de tales derechos es una lesión no sólo a las personas que son sus titulares, sino también a la soberanía popular" (FERRAJOLI, 2011: 13-14).

En virtud de lo anterior, los pueblos indígenas y Garífuna han rechazado iniciativas privadas y gubernamentales de proyectos de desarrollo haciendo uso del discurso de su soberanía popular desde un doble sentido: primero, desde la lógica de la soberanía como garantía negativa, las comunidades entienden que la participación ciudadana no se limita a escoger a quienes ejercerán el poder en su nombre y representación, sino que asumen que participar significa que sus miembros son titulares directos de ese poder y que pueden decidir sobre la forma en que será ejercido en sus territorios, pues de lo que ahora se trata es que las comunidades sean el poder y no que lo escojan (QUESADA, 2013: 108).

Segundo, desde la lógica de la soberanía como garantía positiva, las comunidades entienden que sus miembros son titulares de unos derechos humanos que imponen límites y vínculos a las autoridades estatales cuando se trata de adoptar decisiones que puedan afectarlos, ya que a la luz del artículo 64 constitucional ni siquiera una mayoría absoluta puede aplicar leyes y disposiciones gubernativas o de cualquier otro orden que regulen el ejercicio de tales derechos, si los disminuyen, restringen o tergiversan ${ }^{3}$.

En este orden de ideas, el tribunal interamericano ha establecido que la legitimidad democrática de determinados hechos o actos en una sociedad está limitada por la protección de los derechos humanos, de modo que la existencia de un verdadero régimen democrático está determinada por sus características tanto formales como sustanciales, en donde la protección de tales derechos "constituye un límite infranqueable a la regla de mayorías, es decir, a la esfera de lo "susceptible de ser decidido"” (CORTE IDH, 2011: 238-239).

Por su parte, para la Sala de lo Constitucional los derechos humanos constituyen un elemento estructural del ordenamiento jurídico y un valor esencial del Estado de derecho por lo que deben quedar fuera del alcance de la acción estatal, ya sea por medio de la ley, de la actividad administrativa o de los tribunales de justicia. En consecuencia, la esfera de libertad que los derechos humanos garantizan "no puede ser tocada por ninguna autoridad, porque es [la persona], no

$3 \quad$ Artículo 64: "No se aplicarán leyes y disposiciones gubernativas o de cualquier otro orden, que regulen el ejercicio de las declaraciones, derechos y garantías establecidos en esta Constitución, si los disminuyen, restringen o tergiversan”. 
la sociedad, quien tiene la dignidad y, en consecuencia, corresponde a [ella] la titularidad de los derechos fundamentales" (SCO, 2015: 9).

\section{La autodeterminación de los pueblos}

El derecho a la libre determinación de los pueblos constituye un principio fundamental del derecho internacional. Está contenido en diferentes instrumentos de los que el Estado de Honduras forma parte, como la Carta de las Naciones Unidas (art. 1), el Pacto Internacional de Derechos Económicos, Sociales y Culturales (art. 1) y el Pacto Internacional de Derechos Civiles y Políticos (art. 1). De acuerdo con el Comité para la Eliminación de la Discriminación Racial, el derecho a la libre determinación tiene dos aspectos: uno interno, que implica el derecho de todos los pueblos a llevar adelante su desarrollo económico, social y cultural sin injerencias del exterior, y uno externo, que implica "que todos los pueblos tienen derecho a determinar libremente su condición política y el lugar que deben ocupar en la comunidad internacional sobre la base del principio de igualdad de derechos [...] (CEDR, 1996: 4).

A diferencia de la mayoría de tratados internacionales que conciben a las personas como titulares individuales de derechos, el Convenio 169 reconoce derechos colectivos que son esenciales para la supervivencia física y cultural de los pueblos indígenas y Garífuna, entre los que destacan, los derechos a la propiedad colectiva de sus tierras, territorios y bienes naturales, a mantener sus culturas, al autogobierno y la autodeterminación, y a que se les solicite su consentimiento libre, previo e informado en decisiones que les puedan afectar. El derecho de los pueblos indígenas y Garífuna a la autodeterminación se expresa concretamente en su facultad de autogobernarse, es decir, en el derecho a poseer, disfrutar y controlar sus tierras y territorios, así como a disponer de los bienes naturales que se encuentran en ellos (ÁLVAREZ, 2008). En este sentido, el ejercicio del derecho a la autodeterminación complementa el ejercicio de otros derechos, entre los que se destacan algunos derechos políticos como

[...] participar en la adopción de decisiones en asuntos que afectan a sus derechos y la obligación de los Estados de celebrar consultas y cooperar con ellos para obtener su consentimiento libre, previo e informado antes de adoptar y aplicar medidas legislativas o administrativas que los afecten (OACNUDH, 2013: 5).

En virtud de lo anterior, que sean consultados y que se obtenga su consentimiento cuando el Estado pretenda aprobar y desarrollar proyectos de cualquier tipo que puedan modificar jurídica o materialmente sus territorios, constituye un elemento esencial de su derecho a la autodeterminación. Si bien es cierto que este derecho puede generar preocupación por su posible efecto en la integridad territorial estatal en caso que los pueblos indígenas y Garífuna exijan determinados niveles de independencia, los estándares internacionales establecen una concepción equilibrada 
de dicho derecho, pues tal como lo establece el artículo 46.1 de la Declaración de las Naciones Unidas para los derechos de los Pueblos Indígenas (en adelante, la Declaración), la autodeterminación no "se entenderá en el sentido de que autoriza o alienta acción alguna encaminada a quebrantar o menoscabar, total o parcialmente, la integridad territorial o la unidad política de Estados soberanos e independientes".

De esta manera, el derecho a la autodeterminación se expresa por medio de los siguientes seis elementos: (a) autonomía o autogobierno en cuestiones relativas a sus asuntos internos y locales, así como a los medios de financiar sus funciones de forma autónoma; (b) respeto por el principio de consentimiento libre, previo e informado; (c) participación plena y efectiva en cada etapa de cualquier gestión que pueda afectarles directa o indirectamente; (d) consulta antes de cualquier acción o gestión que pueda tener un impacto en sus territorios, su cultura o sus instituciones; (e) reconocimiento formal de sus instituciones tradicionales, sistemas de justicia y resolución de conflictos, y modos de organización socio-política; y (f) reconocimiento de su derecho a definir y perseguir libremente su desarrollo económico, social y cultural (ONU, 2009: 14-15).

Para hacer efectivo el derecho a la autodeterminación de los pueblos indígenas y Garífuna, Honduras tiene la obligación de adoptar todas las medidas legislativas y de otro carácter que sean pertinentes, ya que, en virtud de una regla básica del derecho internacional, "todo Estado Parte en un tratado tiene el deber jurídico de adoptar las medidas necesarias para cumplir con sus obligaciones conforme al tratado, sean dichas medidas legislativas o de otra índole" (Corte IDH, 1986: 30). No obstante, el hecho de que se requieran tales medidas no significa que la garantía de los derechos de estos pueblos "dependa exclusivamente de la promulgación de disposiciones constitucionales o legislativas, que suelen ser de por sí insuficientes" (DULITZKY, 2004: 89).

En este sentido, el Estado hondureño tiene la obligación de adaptar su legislación interna a los estándares internacionales relativos a los derechos de los pueblos indígenas y Garífuna consagrados en el Convenio 169, la Convención Americana y la Declaración, mediante la supresión de normas y prácticas de cualquier naturaleza que entrañen una violación a tales estándares, y a través de la expedición de normas y el desarrollo de prácticas conducentes a la efectiva realización de sus derechos (CIDH, 1999: 207). Por el incumplimiento de la obligación estatal de adoptar disposiciones de derecho interno a la luz del artículo 2 de la Convención Americana, el tribunal interamericano ya ha condenado al Estado hondureño con respecto a la ausencia de normatividad o de práctica adecuada para hacer efectivo el procedimiento de la consulta (CIDH, 2015: 199).

Como lo señala la Sala de lo Constitucional, en relación con la soberanía popular y la autodeterminación de los pueblos vinculadas con la participación democrática,

[...] el Gobierno de la República debe sustentarse en los principios de la soberanía popular, la autodeterminación de los pueblos y la democracia participativa, esta última, pilar fundamental para el sustento de un Estado de derecho, la que se refuerza y se profundiza con la participación permanente, ética y responsable de la ciudadanía en un marco de legalidad conforme al

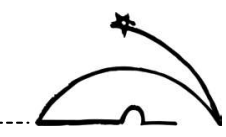


respectivo orden constitucional. La participación ciudadana es un elemento necesario y pleno para el efectivo ejercicio de la democracia a efecto de promover y fomentar diversas formas de participación y de esta forma lograr el fortalecimiento de la democracia, que es máximo anhelo de todo Estado de Derecho, en busca de satisfacer al goce de la justicia, la libertad, la cultura y el bienestar económico y social como lo declara nuestra Carta Magna (SCO, 2017: 20).

A la luz de todo lo anterior, cuando el Estado de Honduras no garantiza la participación efectiva de los pueblos en los procesos de aprobación y ejecución de proyectos de desarrollo sobre sus tierras, ríos y bosques, éstos lo sienten y viven como una práctica de despojo y un ataque a su identidad y modo de subsistencia, frente a lo cual no es de extrañar que se opongan a pesar de las amenazas, los hostigamientos, la criminalización y los riesgos para su vida e integridad. Por ello, las autoridades públicas, especialmente las que pertenecen al sistema de seguridad y justicia, deben comprender que

[...] la protesta indígena no puede ser considerada una acción “ilegal”, ya que los mismos est[án] legitimados, por el [...] Convenio 169 de la OIT, el cual les ampara para reclamar su derecho de ser consultados 'antes' de emprenderse o autorizarse cualquier programa de prospección o explotación de los recursos existentes en sus tierras. [Por tanto, los indígenas que defienden sus territorios] no realiza[n] de manera ilegal la obstaculización de la ejecución de [un proyecto de desarrollo...], [si no es] consultado con la mayoría de la comunidad indígena, derecho que tiene legitimidad en virtud del Convenio 169 de la OIT (CORTE DE APELACIONES DE LO PENAL DE SAN PEDRO SULA, 2013).

En síntesis, las autoridades hondureñas tienen que asumir que la mejor forma de tratar las cuestiones ambientales es con la participación de todas las personas interesadas en los procesos de toma de decisiones en el nivel que corresponda, $y$, en consecuencia, tienen la obligación de procurar la creación de mecanismos para consultar y facilitar la participación en dichos procesos de las organizaciones, grupos y particulares interesados o potencialmente afectados directamente con los proyectos de desarrollo que puedan generar perjuicios en el medio ambiente y en la salud de los mismos. Es importante subrayar que el gobierno tiene la obligación de establecer

[...] procedimientos con miras a consultar los pueblos interesados, antes de emprender o autorizar cualquier programa de prospección o exploración de los recursos existentes en sus tierras" (SCO, 2017: 20), ya que en "relación a la protección de los derechos de los pueblos indígenas y tribales, se garantiza la protección de los recursos naturales existentes en sus tierras, incluyendo la participación en la utilización, administración y conservación de dichos recursos (Ibid.).

La normativa y jurisprudencia analizada anteriormente constituye el horizonte hacia el cual 
debe dirigirse el Estado de Honduras si realmente quiere mostrar su voluntad política para prevenir y reducir al mínimo los conflictos sociales vinculados con la aprobación y ejecución inconsultas de proyectos de desarrollo, y con la defensa de los territorios. En este sentido, no puede ignorar los principios de soberanía popular y autodeterminación de los pueblos, de los cuales derivan el derecho a la consulta como herramienta democrática para asegurar que el derecho de los pueblos indígenas y Garífuna a sus territorios y a los bienes naturales existentes en él no sea jurídicamente extinguido o alterado sin que medie la consulta y el consentimiento pleno e informado de la comunidad afectada (CIDH, 2009: 186-187).

Sin embargo, no basta con tener claridad sobre los derechos de los pueblos y las obligaciones del Estado cuando se trata de aprobar proyectos extractivos dentro de los territorios, ya que es fundamental la organización y formación de los primeros para que desaprendan las cosas que han aprendido con el sistema y aprendan en clave indígena, ya que "cuando se empoderan, cuando inician la descolonización cultural, nunca vuelven a ser lo mismo; y la diversidad étnica y cultural que representan retorna como un valor de la realidad social que paulatinamente va conquistando su propio espacio en la identidad nacional" (BARAHONA, 2009: 270, 281).

\section{Condiciones mínimas para garantizar el principio de la soberanía popular y el derecho a la autodeterminación frente a proyectos de desarrollo}

Antes de aprobar un plan de desarrollo u otorgar una concesión extractiva que afecte los territorios de los pueblos indígenas y Garífuna, el Estado tiene la obligación de cumplir tres condiciones fundamentales para revestir de legalidad y legitimidad dicha acción: realizar una consulta previa e informada, garantizar la participación razonable en los beneficios y efectuar un estudio previo de impacto ambiental y social realizado con participación de la comunidad (CIDH, 2009: 225). Aunque a la luz de la jurisprudencia constitucional estas tres condiciones forman parte del derecho interno mediante su incorporación al "bloque de constitucionalidad", lo ideal es que sean desarrolladas en una ley especial; sin embargo, tales condiciones son ignoradas en la propuesta de ley que está siendo analizada en el Congreso Nacional, ya que presenta problemas con su contenido y adecuación a los estándares internacionales en materia de consulta previa, y con el proceso que se llevó a cabo para su elaboración y socialización con los pueblos indígenas y Garífuna (RELATORA ESPECIAL DE LAS NACIONES UNIDAS SOBRE LOS DERECHOS DE LOS PUEBLOS INDÍGENAS, 2016: 3ss.).

De esta manera, el Estado hondureño incumple con su obligación internacional de adoptar, en base a los respectivos procesos constitucionales y a las disposiciones de la Convención Americana y el Convenio 169, las medidas legislativas o aquellas de otro carácter que fueran necesarias para hacer efectivos los derechos y libertades consagrados en ellas. Esto implica (a) dictar las medidas necesarias para hacer efectivos los derechos y libertades reconocidos, (b) no dictar medidas que violenten derechos fundamentales y (c) adecuar la normativa que sea contraria 
a tales tratados, pues en virtud de los artículos 26 y 27 de la Convención de Viena sobre el Derecho de los Tratados del 23 de mayo de 1969, los mismos deben ser cumplidos de buena fe y no se pueden invocar disposiciones de derecho interno como justificación de su incumplimiento.

\section{La consulta previa e informada}

La participación ciudadana de los pueblos es un elemento central del principio de la soberanía popular y el derecho a la autodeterminación, razón por la cual el Estado tiene el deber de establecer normas y desarrollar prácticas que aseguren dicha participación mediante consultas efectivas que permitan que sus miembros den su consentimiento pleno e informado en relación con la realización de cualquier proyecto en sus territorios. Esto requiere "como mínimo, que todos los integrantes de la comunidad estén plenamente enterados de la naturaleza y consecuencias del proceso" (CIDH, 2004: 142), y de los posibles riesgos ambientales y de salubridad que podrían correr, si es que los hubieran, en caso de aceptar la realización de un proyecto, plan de desarrollo o de inversión (CORTE IDH, 2007: 133). Para asegurar que la consulta se constituya en un ejercicio efectivo de participación democrática, esta debe regirse por una serie de principios rectores ineludibles.

Primero, el principio de buena fe, que implica que el Estado realice la consulta en un clima de confianza, con la intención de tomar en cuenta la opinión que expresen los pueblos consultados sin que se les trate de engañar, traicionar o brindar información sesgada o parcial. Así, los procesos de consulta y la decisión de las comunidades no deben considerarse una mera formalidad para legitimar los proyectos (CIDH, 2009: 122-124 y JULIÁ, 2011: 33-34). En este orden de ideas, "la mera socialización con la comunidad o brindar información no necesariamente cumple con los elementos mínimos de una consulta previa adecuada, en la medida que no constituye un diálogo genuino como parte de un proceso de participación con miras a alcanzar un acuerdo" (CORTE IDH, 2015: 173).

Es importante resaltar que el principio de buena fe en los procesos de consulta es clave para que los mismos y los resultados que se obtengan sean considerados válidos y legítimos para los pueblos indígenas y Garífuna, el Estado y las empresas, y compatibles con los estándares internacionales de derechos humanos sobre la materia (CIDH, 2015: 108). Consecuentemente, este principio es incompatible con algunas prácticas de las autoridades hondureñas, tales como la destrucción de la cohesión social de las comunidades mediante la corrupción de algunos de sus liderazgos, el establecimiento de liderazgos paralelos o la realización de negociaciones con personas que individualmente son contrarias a los estándares sobre consulta y participación comunitaria (Ibid.: 123).

Segundo, el principio de previa consulta, ya que el momento en que esta se realice es clave para un verdadero ejercicio de decisión por parte de las comunidades posiblemente afectadas. La consulta debe realizarse en las primeras etapas del plan de desarrollo o inversión y no 
solamente cuando surja la necesidad de obtener la aprobación de la comunidad. El aviso anticipado proporciona un tiempo para la discusión interna dentro de las comunidades y para ofrecer una respuesta apropiada al Estado. Tercero, el principio de libertad, en tanto que un verdadero ejercicio de consulta exige que se realice libre de injerencias externas, de coerción, intimidación y manipulación. Por lo tanto, condicionar servicios sociales básicos como la educación o la salud a que den su consentimiento a un proyecto, supone una coerción con respecto a la libre decisión de las comunidades consultadas, además de una violación a sus derechos económicos, sociales y culturales que jamás deben ser condicionados a la realización de un proyecto. De esta manera, plantear a las comunidades el dilema entre desarrollarse o continuar en la pobreza puede ser considerado una forma de coerción (Ibid.: 118; JULIÁ, 2011: 34-35).

Cuarto, el principio de información en el sentido de que las comunidades deben contar con la suficiente información que les permita tomar una decisión con respecto al proyecto consultado. Esta información debe incluir (a) la naturaleza, envergadura, impacto y alcances del proyecto; (b) la razón u objetivo del proyecto; (c) su justificación; (d) duración y tiempos del proyecto; (e) lugares y zonas que serán afectadas; (f) evaluación del probable impacto económico, social, cultural y ambiental; $(\mathrm{g})$ posibles riesgos y beneficios; $\mathrm{y}(\mathrm{h})$ elementos de un posible desplazamiento (CIDH, 2009: 120-121 y JULIÁ, 2011: 36).

Y quinto, la consulta debe ser culturalmente adecuada, es decir, debe realizarse a través de procedimientos culturalmente apropiados y conformes con las costumbres y métodos tradicionales para la toma de decisiones de los pueblos indígenas y Garífuna (CORTE IDH, 2007: 131). Todos los asuntos relacionados con el proceso de consulta, ya sea para obtener el consentimiento del pueblo, determinar los beneficios razonables y las personas beneficiarias, la indemnización adecuada y contar con su cooperación para la realización de estudios de impacto social y ambiental, deben ser determinados y resueltos por dicho pueblo "de conformidad con sus costumbres y normas tradicionales" (CORTE IDH, 2008: 27) y tomando en cuenta "la voluntad de la totalidad del pueblo canalizada a través de los mecanismos consuetudinarios correspondientes" (CIDH, 2009: 113).

\section{Participación en los beneficios}

El Estado tiene la obligación de garantizar que los miembros de los pueblos participen activamente en la determinación de los beneficios razonables que pueden producir los planes o proyectos que se pretenden llevar a cabo dentro de sus territorios, así como de la aplicación comercial de sus conocimientos tradicionales sobre el uso de dichos recursos, ya que uno de los objetivos que se busca con ello es que las condiciones de vida de sus comunidades mejoren (CIDH, 2015: 116). Por ello, las autoridades deben garantizar que en el marco de los procedimientos de consulta previa se establezcan los beneficios que serán percibidos por las comunidades y las posibles indemnizaciones por cualquier daño ambiental, teniendo en cuenta sus propias prioridades 
de desarrollo, pues son las propias comunidades las que saben a la perfección cuáles son sus necesidades (CIDH, 2009: 1137, recomendación 5 y Íd., 2007: 248).

Por otro lado, la determinación de los beneficios y de las personas beneficiarias debe ser hecha en consulta con las comunidades y no unilateralmente por el Estado o por las empresas beneficiarias de las concesiones. En caso que surja un conflicto interno entre los miembros del pueblo indígena o Garífuna acerca de quién tiene la calidad de persona beneficiaria, este asunto debe ser resuelto por el pueblo mismo de conformidad con sus propias costumbres y normas tradicionales, y no por el Estado (CIDH, 2009: 118). También es importante insistir que no debe confundirse la participación en los beneficios de un proyecto con la dotación de servicios sociales básicos que de cualquier modo corresponde proporcionar al Estado en virtud de sus obligaciones constitucionales en materia de derechos económicos, sociales y culturales, tales como centros de salud, pavimentación de calles, construcción o reparación de centros educativos, desarrollo de proyectos de electrificación o de servicios de agua potable, entre otros (Ibid.: 98-100).

\section{Realización de estudios de impacto}

El Estado tiene que garantizar que no se emitirá ninguna concesión dentro de los territorios de las comunidades a menos y hasta que entidades independientes y técnicamente capaces, bajo la supervisión del Estado, realicen un estudio previo de impacto social y ambiental que evalúe la incidencia social, espiritual y cultural y sobre el medio ambiente que las actividades previstas del proyecto pueden tener sobre tales comunidades. El objetivo de estos estudios no es sólo tener alguna medida objetiva del posible impacto sobre los bienes naturales y las personas, sino también asegurar que los miembros de las comunidades tengan conocimiento de los posibles riesgos ambientales, culturales, sociales, económicos y de salud, a fin de que acepten el plan de desarrollo o inversión propuesto con conocimiento y de forma voluntaria. Sin embargo, el Estado debe tener claridad que la finalidad última de este tipo de estudios es preservar, proteger y garantizar la relación especial de los pueblos indígenas y Garífuna con sus territorios y garantizar su subsistencia como pueblos (CORTE IDH, 2007: 129).

Los estudios de impacto deben realizarse y concluirse de manera previa a la aprobación y otorgamiento de las concesiones respectivas, ya que uno de los fines de la exigencia de los mismos es garantizar el derecho de las comunidades a ser informadas acerca de todos los proyectos que se pretendan ejecutar en su territorio. Consecuentemente, la obligación del Estado hondureño de supervisar estos estudios coincide con su deber de asegurar la efectiva participación de los pueblos indígenas y Garífuna en el proceso de otorgamiento de concesiones dentro de sus territorios. Considerando que según el artículo 59 constitucional el fin supremo del Estado es la persona humana, éste no debe aprobar un proyecto que pueda amenazar la supervivencia física o cultural de un pueblo y cuando uno en ejecución esté causando daños ecológicos significativos o de otro tipo a los territorios colectivos, debe declararlo ilegal y, en consecuencia, suspenderlo 
inmediatamente, reparar los daños ambientales e investigar y sancionar a las personas y empresas responsables de los mismos (CIDH, 2009: 90).

Si se quiere asegurar que los estudios de impacto tengan la legitimidad necesaria para generar confianza en todos los actores involucrados, el Estado debe (a) ser el responsable de su realización, llevándolos a cabo directamente o encomendándolos a terceros bajo su estricta supervisión; obviamente, tales estudios no tendrían legitimidad si fueran realizados por personal o contratistas de las empresas concesionarias o si la selección de quienes los realicen no se basara en las pericias técnicas requeridas (Ibíd.: 101-102). Y (b) garantizar la participación de los pueblos de las comunidades a la luz del artículo 7.3 del Convenio 169 que establece que las autoridades deben velar que los estudios se efectúen "en cooperación con los pueblos interesados, a fin de evaluar la incidencia social, espiritual y cultural y sobre el medio ambiente que las actividades de desarrollo previstas puedan tener sobre esos pueblos".

\section{La obligatoriedad de la consulta frente a proyectos a pequeña y gran escala}

El fin último de la consulta es llegar a un acuerdo entre el Estado y los pueblos indígenas y Garífunas, u obtener su consentimiento en los asuntos que impliquen la afectación de sus derechos. Por tanto, no debe "limitarse únicamente a una notificación o a un trámite de cuantificación de daños" (CIDH, 2007: 248), pues la idea es que estos pueblos tengan la capacidad de influir en el proceso y en las decisiones tomadas sobre un proyecto a ejecutarse en sus territorios (CIDH, 2016: 96-97), lo que implica "la evidencia de modificación de los planes o proyectos basados en las opiniones, preocupaciones y aportaciones de los pueblos indígenas y tribales". Esto requiere flexibilidad de todas las partes involucradas

\footnotetext{
[...] para acomodar los distintos derechos e intereses en juego, dado que los planes o proyectos de extracción, explotación o concesiones extractivas afecten de manera sustancial al derecho de propiedad indígena y otros derechos conexos. El deber de los Estados es el de ajustar o incluso cancelar el plan o proyecto con base en los resultados de la consulta con los pueblos indígenas, o, en defecto de tal acomodo, el de proporcionar motivos objetivos y razonables para no haberlo hecho (CIDH, 2009: 124).
}

Bajo estos parámetros, el Estado no puede dejar de tomar en consideración los resultados de la consulta en el diseño final de los proyectos de desarrollo, pues hacerlo implica una vulneración al principio de buena fe que debe regir la obligación de consultar. Cuando la modificación o acomodo de un proyecto en virtud de los resultados de la consulta no sea posible por motivos objetivos, razonables y proporcionales a un interés legítimo, "la decisión que lo apruebe debe argumentar, de forma razonada, cuáles son dichos motivos. Esa decisión, y las razones que justifican la no incorporación de los resultados de la consulta al plan final, deben ser formalmente 
comunicadas al pueblo indígena respectivo" para que estos tengan la posibilidad de recurrirla ante instancias superiores "a través de procedimientos adecuados y efectivos, que evalúen la validez y pertinencia de dichas razones, así como el equilibrio entre los derechos e intereses en juego" (Ibíd.: 124; CIDH, 2016: 81).

Sin embargo, cuando se trate de proyectos de desarrollo a gran escala cuya magnitud o dimensión e impacto humano y social pueden tener un mayor impacto dentro del territorio de los pueblos indígenas o Garífunas y afectar la integridad de sus tierras y bienes naturales, el Estado no solamente tiene la obligación de consultarles, sino también de obtener su consentimiento (CIDH, 2007: 134). La obtención del consentimiento constituye una protección reforzada de derechos esenciales como la vida y la identidad cultural, cuyos contenidos básicos pueden resultar seriamente afectados frente a la ejecución de proyectos que impliquen, por ejemplo, (a) el desplazamiento de los pueblos o comunidades de sus territorios tradicionales y su reubicación permanente, (b) la explotación de los bienes naturales que los privaría de su capacidad de usarlos y gozarlos para su subsistencia, o (c) el depósito o almacenamiento de materiales peligrosos en sus tierras (CIDH, 2009: 126; Id., 2016: 100).

\section{A modo de conclusión}

Los pueblos indígenas y Garífuna tienen el derecho a participar en los procesos de diseño, licitación, concesión, ejecución y evaluación de los proyectos de desarrollo que se lleven a cabo en sus territorios, y el Estado de Honduras tiene la obligación de garantizar que dichos pueblos sean consultados sobre los asuntos que puedan afectarlos, con el fin de obtener su consentimiento libre e informado (CIDH, 2007: 157). En consecuencia, la exploración y/o explotación de los bienes naturales en los territorios ancestrales sin la consulta y consentimiento de estos pueblos "viola su derecho a la propiedad y su derecho a participar en el gobierno" (CIDH, 2009: 114).

A la luz de nuestro marco constitucional, el Estado es un instrumento o una herramienta que sirve y existe en función del desarrollo de la dignidad de las personas, por lo que se ha constituido, como lo señala el artículo 1 de la Constitución, para asegurar a las personas "el goce de la justicia, la libertad, la cultura y el bienestar económico y social". Bajo esta concepción instrumental del Estado, su legitimidad descansa en la protección de las personas, de sus derechos y dignidad, lo cual, a su vez, es la "causa o razón social de ese artificio que es el Estado" (FERRAJOLI, 2001: 35-36). Como lo ha establecido la Sala de lo Constitucional, "el Estado sólo debe existir, en última instancia, para proteger los derechos fundamentales, pues éstos son fundamento del orden político y de la paz social, sin respeto de los derechos fundamentales no puede haber democracia constitucional ni tampoco, siquiera concordia civil" (SCO, 2008: 48).

En consecuencia, las instituciones públicas deben tener siempre presente que la causa de su existencia y su razón de ser es el respeto, defensa y promoción de los derechos humanos, cuyos titulares son el "alfa y omega" de las normas y prácticas estatales (SCO, 2014: 9). Por tanto, en 
materia de proyectos de desarrollo deben ser conformes con los estándares constitucionales e internacionales de derechos humanos a la luz del principio de la soberanía popular y el derecho a la autodeterminación, que exigen la garantía de los derechos a la consulta y a la participación democrática de los miembros de los pueblos indígena y Garífuna, únicos sujetos políticos en los que reside legítimamente el poder soberano.

Ante la falta de cumplimiento sistemático por parte del Estado de las condiciones mínimas para una consulta previa, libre e informada, los pueblos indígenas y Garífuna tienen en la normativa y jurisprudencia constitucional e interamericana las herramientas necesarias para (a) evidenciar la compatibilidad o incompatibilidad de la actual legislación y políticas públicas en materia de gestión de los bienes naturales con las obligaciones estatales internacionales de derechos humanos; (b) exigir que las normas nacionales garanticen la realización de procesos de consulta adecuadas a los estándares interamericanos; y (c) desafiar a los tribunales nacionales a que, ante las antinomias, lagunas o insuficiencias normativas en materia de consulta previa, garanticen la supremacía constitucional y convencional ${ }^{4}$, es decir, la realización de consultas previas destinadas a obtener el consentimiento libre, previo e informado de los pueblos antes de adoptar cualquier medida que pueda incidir sobre sus vidas, derechos, intereses y relación con sus territorios, y, de este modo, puedan plantear sus propias propuestas.

\section{Bibliografía}

\section{Libros y artículos}

ÁLVAREZ MOLINERO, Natalia. Pueblos indigenas y derecho de autodeterminación. ¿Hacia un derecho internacional multicultural? Universidad de Deusto, Bilbao, 2008.

BARAHONA, Marvin. Pueblos indigenas, Estado y memoria colectiva en Honduras. Editorial Guaymuras, Editorial Casa San Ignacio, enero de 2009.

BARTOLOMÉ RUÍZ, Castor M. M. El Movimiento de los Sin Tierra en Brasil. Propiedad o alteridad, dilema de los derechos humanos. Universidad de Deusto, Bilbao, 2006.

COSTA MORATA, Pedro. "Destrucción e injusticia ecológica: El caso de América Latina”, en VICENTE GIMÉNEZ, Teresa (Ed.), Justicia ecológica en la era del Antropoceno, Editorial Trotta, Madrid, 2016. p. 189-208.

FERRAJOLI, Luigi. Los fundamentos de los derechos fundamentales: debate con Luca Baccelli, Michelangelo Bovero, Riccardo Guastini, Mario Jori, Anna Pintore, Ermanno Vitale y Danilo Zolo. Trotta, Madrid. 2001.

$4 \quad$ Supremacía Constitucional: "Artículo 320. En caso de incompatibilidad entre una norma constitucional y una legal ordinaria, se aplicará la primera". Supremacía Convencional: "Artículo 18. En caso de conflicto entre el tratado o convención y la ley, prevalecerá el primero". 
FERRAJOLI, Luigi. Principia iuris. Teoría del derecho y de la democracia. 2. Teoría de la democracia. Trotta, Madrid, 2011.

DULITZKY, Ariel E. “Alcance de las obligaciones internacionales de derechos humanos”, en MARTIN, Claudia, RODRÍGUEZ-PINZÓN, Diego y GUEVARA B., José A. (Comps.). Derecho Internacional de los Derechos Humanos. Universidad Iberoamericana/American University/Fontamara, México, 2004. p. 79-117

JULIÁ SANTIAGO, José Juan. El derecho a la consulta de los pueblos indígenas: La importancia de su implementación en el contexto de los proyectos de desarrollo a gran escala. Oficina en México del Alto Comisionado de las Naciones Unidas para los Derechos, México, 2011.

MEJÍA RIVERA, Joaquín A. y FERNÁNDEZ, Víctor (Coord.). El golpe de Estado en Honduras desde una perspectiva de los derechos humanos. Editorial San Ignacio/MADJ, Tegucigalpa, junio de 2010.

MEJÍA RIVERA, Joaquín A. "El peligro de las reformas penales en un contexto de autoritarismo". Revista Envío-Honduras, año 15, N 52, ERIC-SJ, Tegucigalpa, Honduras, mayo 2017. pp. 15-20.

MEJÍA RIVERA, Joaquín A. y JEREZ MORENO, Rafael. “La reelección presidencial en Honduras: La sentencia espuria y la falacia de un derecho humano”, en MEJÍA RIVERA, Joaquín A. (Coord.), La reelección presidencial en Centroamérica: ¿un derecho absoluto? Editorial San Ignacio, Tegucigalpa, noviembre de 2018. p. 51-82

QUESADA TOVAR, Carlos Erin. Derecho a la consulta previa para comunidades campesinas. Tesis de Maestría, Facultad de Derecho, Ciencias Políticas y Sociales de la Universidad Nacional de Colombia, Bogotá, Colombia, 2013.

\section{Sistema Interamericano de Derechos Humanos}

Comisión Interamericana de Derechos Humanos. Acceso a la Justicia e Inclusión Social: El camino hacia el fortalecimiento de la democracia en Bolivia. Doc. OEA/Ser.L/V/II, Doc. 34, 28 de junio de 2007.

Comisión Interamericana de Derechos Humanos. Derechos de los pueblos indígenas y tribales sobre sus tierras ancestrales y recursos naturales, Normas y jurisprudencia del Sistema Interamericano de Derechos Humanos. OEA/ Ser.L/V/II. Doc. 56/0, 30 diciembre 2009.

Comisión Interamericana de Derechos Humanos. Honduras: Derechos humanos y golpe de Estado. 30 de diciembre de 2009 .

Comisión Interamericana de Derechos Humanos. Observaciones preliminares de la visita de la CIDH a Honduras, 3 de agosto de 2018 . 
Comisión Interamericana de Derechos Humanos. Pueblos indígenas, comunidades afrodescendientes y recursos naturales: Protección de derechos humanos en el contexto de actividades de extracción, explotación y desarrollo. OEA/Ser.L/V/II. Doc. 47/15, 31 diciembre 2015.

Comisión Interamericana de Derechos Humanos. Situación de derechos humanos en Honduras, Organización de los Estados Americanos. OEA/Ser.L/V/II. Doc. 146, Washington, D.C., 27 agosto 2019.

Comisión Interamericana de Derechos Humanos. Situación de derechos humanos en Honduras, Organización de los Estados Americanos. OEA/Ser.L/V/II. Doc. 42/15, Washington, D.C., 31 diciembre 2015.

Corte Interamericana de Derechos Humanos. Caso Castillo Petruzzi y otros Vs. Perú, Sentencia de 30 de mayo de 1999.

Corte Interamericana de Derechos Humanos. Caso Comunidad Garifuna de Punta Piedra y sus miembros Vs. Honduras. Excepciones, Fondo, Reparaciones y Costas, Sentencia de 8 de octubre de 2015.

Corte Interamericana de Derechos Humanos. Caso Comunidad Garifuna Punta Piedra y sus miembros Vs. Honduras. Fondo, Reparaciones y Costas, Sentencia de 8 de octubre de 2015.

Corte Interamericana de Derechos Humanos. Caso del Pueblo Saramaka Vs. Surinam, Excepciones Preliminares, Fondo, Reparaciones y Costas. Sentencia del 28 de noviembre de 2007.

Corte Interamericana de Derechos Humanos. Caso del Pueblo Saramaka Vs. Surinam, Interpretación de la Sentencia de Excepciones Preliminares, Fondo, Reparaciones y Costas, Sentencia de 12 de agosto de 2008.

Corte Interamericana de Derechos Humanos. Exigibilidad del derecho de rectificación o respuesta (arts. 14.1, 1.1 y 2 Convención Americana sobre Derechos Humanos), Opinión Consultiva OC-7/86 del 29 de agosto de 1986.

Corte Interamericana de Derechos Humanos. Caso Gelman Vs. Uruguay, Fondo y reparaciones, Sentencia de 24 de febrero de 2011.

Corte Interamericana de Derechos Humanos . La colegiación obligatoria de periodistas (Arts. 13 y 29 de la Convención Americana sobre Derechos Humanos), Opinión Consultiva OC-5/85 del 13 de noviembre de 1985.

\section{Naciones Unidas}

Comentarios de la Relatora Especial de las Naciones Unidas sobre los derechos de los pueblos indígenas en relación con el Anteproyecto de Ley Marco de consulta libre, previa e informada a los pueblos indigenas y afrohondureños (Honduras), 22 de diciembre de 2016. 
Directrices sobre las cuestiones relativas a los pueblos indigenas, Grupo de Apoyo Interinstitucional sobre Cuestiones Indígenas (IASG), Naciones Unidas, New York y Ginebra, 2009.

Informe de la Relatora Especial sobre los derechos de los pueblos indígenas sobre su visita a Honduras, A/HRC/33/42/ Add.2, 21 de julio de 2016.

La Comisión Interamericana de Derechos Humanos y su Relatoría Especial para la Libertad de Expresión y la Oficina del Alto Comisionado de las Naciones Unidas para los Derechos Humanos en Honduras expresan su preocupación ante la aprobación de reformas al Código Penal hondureño regresivas para los derechos humanos y la libertad de expresión, Comunicado conjunto, Washington, D.C. y Tegucigalpa, 23 de febrero de 2017.

Oficina del Alto Comisionado de Naciones Unidas para los Derechos Humanos en Honduras. Informe anual 2018 sobre la situación de derechos humanos en Honduras, Tegucigalpa, 2019.

Oficina del Alto Comisionado de Naciones Unidas para los Derechos Humanos en Honduras. Las violaciones a los derechos humanos en el contexto de las elecciones de 2017 en Honduras, Tegucigalpa, 2018.

Oficina del Alto Comisionado de Naciones Unidas para los Derechos Humanos en Honduras. Los pueblos indígenas y el sistema de derechos de las Naciones Unidas, Nueva York y Ginebra, 2013.

Recomendación general $N^{\circ} 21$, Comité para la Eliminación de la Discriminación Racial, relativa al derecho a la libre determinación, $48^{\circ}$ período de sesiones, U.N. Doc. HRI/GEN/1/Rev.7 at 245 (1996).

\section{Resoluciones judiciales nacionales}

Expediente $N^{\circ}$ 38-2013 de la Corte de Apelaciones de lo Penal de San Pedro Sula, Cortés.

Sala de lo Constitucional, Sentencia recaída en el Recurso Administrativo acumulado 157, 160, 164 y 169-08, de 11 de agosto de 2008 .

Sentencia de la Sala de lo Constitucional de la Corte Suprema de Justicia del Recurso de Amparo Administrativo AA-0406-2013, de fecha de fecha 28 de junio de 2013.

Sentencia de la Sala de lo Constitucional, Recurso de Inconstitucionalidad EXP. SCO - 1165- 2014, 23 de junio de 2017.

Sentencia de la Sala de lo Constitucional de la Corte Suprema de Justicia del Recurso de Inconstitucionalidad vía 
Acción RI-1343-2014 acumulada con el RI-0243-2015, 22 de abril de 2015.

\section{Otros}

Misión de Observación Electoral. Informe final. Elecciones generales. Honduras, Organización de Estados Americanos, 26 de noviembre de 2017.

The Inspection Panel. Informe de Investigación, Honduras: Programa de Administración de Tierras de Honduras, Banco Mundial, Informe No 39933- HN, 12 de junio de 2007.

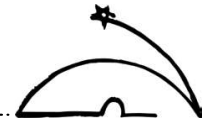

